\title{
CARACTERIZAÇÃO DE UMA BACIA HIDROGRÁFICA UTILIZANDO FERRAMENTAS DE GEOPROCESSAMENTO
}

Paula Eliza Pereira - paulaeliza@engambiental.ufla.br Universidade Federal de Lavras

Marcus Vinícius Ferreira Nunes - mnunes@engambiental.ufla.br Universidade Federal de Lavras

Estefânia Maria Sousa Zákhia - estefstew@gmail.com

Universidade Federal de Lavras

Geovane Fernandes da Silva - gfsilva@engambiental.ufla.br

Universidade Federal de Lavras

Mirian Fátima Alves - mirian@engambiental.ufla.br

Universidade Federal de Lavras

Gilberto Coelho - coelho@deg.ufla.br

Universidade Federal de Lavras 


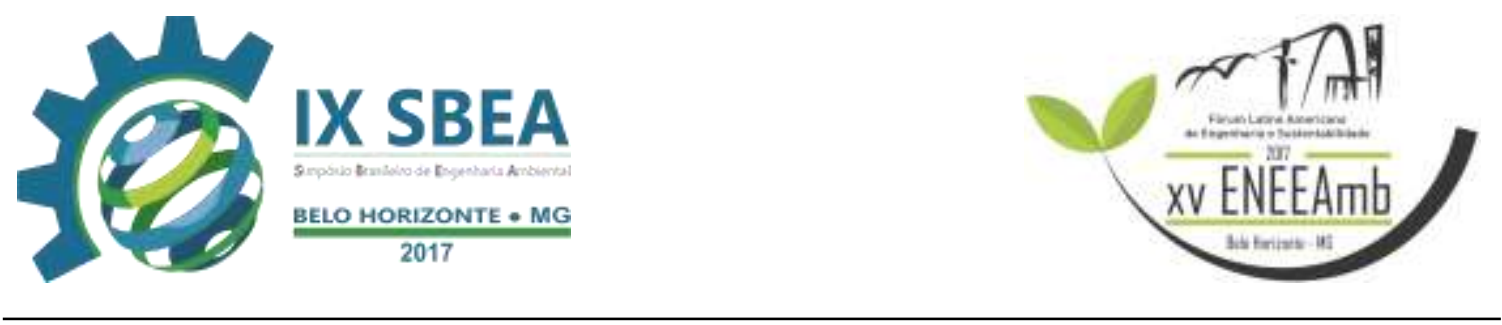

\section{RESUMO}

Bacia hidrográfica consiste de uma unidade geomorfológica de captação natural de água proveniente de eventos de precipitação cujo o escoamento converge para uma seção comum, denominada seção de controle ou exutório da bacia. (MELLO, 2013). O objetivo deste trabalho foi caracterizar uma bacia de quinta ordem individualizada, utilizando dados obtidos por meio de ferramentas de geoprocessamento através do software ArcGIS 10.2.2. Obteve-se como resultado a área da bacia hidrográfica, bem como seu perímetro, altitudes máxima, média e mínima, comprimento do escoamento superficial, declividade e tempo de concentração. Foram gerados mapas temáticos da hidrografia, da declividade, do escoamento superficial direto e também do tempo de concentração de Kirpich. As ferramentas de geoprocessamento têm sido amplamente utilizadas nas áreas relacionadas ao meio ambiente. Tais ferramentas auxiliam na prevenção, controle, monitoramento de impactos ambientais, e também na caracterização de bacias hidrográficas, que possuem grandes extensões, cujo trabalho de campo é dispendioso.

Palavras-chave: Geoprocessamento, Recursos Hídricos, Bacia Hidrográfica.

\section{OBJETIVO}

O objetivo deste trabalho foi caracterizar uma bacia de quinta ordem individualizada, utilizando dados obtidos por meio de ferramentas de geoprocessamento, como o comprimento do escoamento superficial na bacia e na rede de drenagem, o mapa de declividade da bacia e o tempo de concentração pela equação de Kirpich.

\section{METODOLOGIA}

\subsection{INDIVIDUALIZAÇÃO DA BACIA}

Utilizou-se durante os procedimentos do trabalho o software ArcGIS 10.2.2 e o Excel. Pelo ArcGIS, gerou-se os produtos de geoprocessamento. Utilizou-se uma 
imagem do satélite ASTER com latitude $23^{\circ}$ Sul e longitude $45^{\circ}$ Oeste (ASTGTM2_S23W045). Transformou-se o sistema de coordenadas para South America Albers Equal Area Conic. Para a individualização da bacia, fez-se a projeção do modelo numérico de terreno (MNT) no sistema de coordenadas métricas, modificou-se as células para o tamanho de 30x30, e partindo-se do MNT projetado, através da ferramenta fill realizou-se o preenchimento de falhas e depressões, gerando o MNT corrigido. Realizou-se o procedimento duas vezes.

A geração do mapa de direção de fluxo foi feita utilizando a ferramenta flow direction, o mapa de fluxo acumulado foi gerado com a ferramenta flow accumulation. A extração da hidrografia foi realizada utilizando a ferramenta raster calculator, supondo-se uma nascente a cada 500 células de contribuição. Foram feitas as classificações dos cursos d'água a partir desta hidrografia utilizando a metodologia Strahler com a ferramenta Stream Order. Os cursos d'água foram isolados com classificação maior ou igual a 5 com a ferramenta raster calculator, sendo estes cursos segmentados utilizando a ferramenta Stream Link, que secciona todo o curso d'água conforme as confluências nas quais ele encontra-se.

Com a ferramenta raster calculator foi criado um ponto de foz para cada segmento de $5^{\mathrm{a}}$ ordem. Estes pontos foram utilizados para a delimitação das bacias hidrográficas com auxílio da ferramenta Watershed. Para obtermos apenas as hidrografias de $5^{\mathrm{a}}$ ordem, foi utilizado o raster calculator de forma a retornar apenas as hidrografias da ordem condicionada. Com a ferramenta Stream Link, as hidrografias foram segmentadas e fez-se através do raster calculator a foz dos segmentos. Utilizando novamente a ferramenta raster calculator foi escolhida e isolada uma bacia de quinta ordem, sendo está transformada em um polígono com o uso da ferramenta raster to polygon.

Criou-se um novo arquivo para a realização do trabalho com a bacia individualizada. No novo arquivo, adicionou-se o Modelo Numérico de Terreno (MNT), a bacia individualizada e o polígono da bacia. Extraiu-se o MNT usando a ferramenta extract by mask. Obteve-se os dados da bacia tais como altitude, área e perímetro. Utilizou-se as ferramentas flow direction e flow accumulation, e posteriormente o raster 


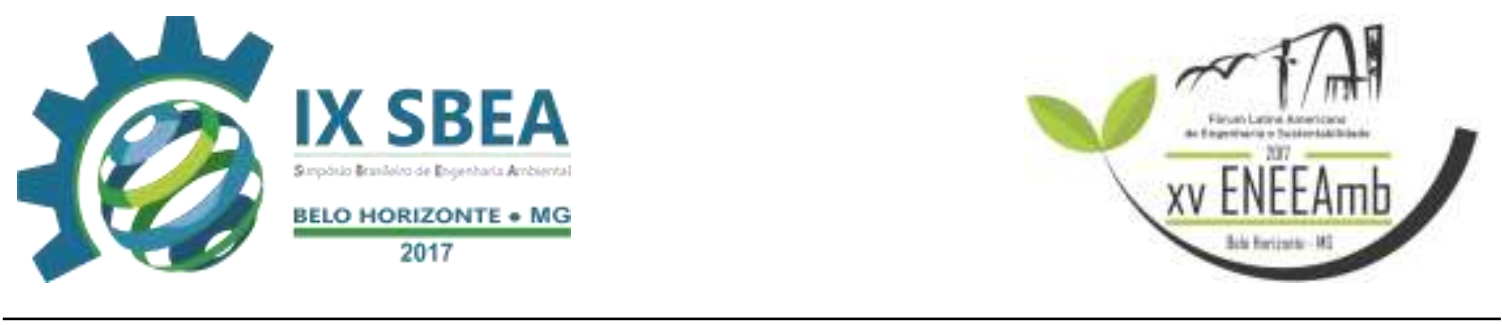

calculator para fazer com que a hidrografia fosse formada a partir do acúmulo de 100 células.

\subsection{DECLIVIDADES DA BACIA E DA REDE HIDROGRÁFICA}

As declividades, em porcentagem, da bacia hidrográfica foram geradas com a ferramenta Slope. Utilizando a ferramenta raster calculator foram obtidas as declividades para a rede hidrográfica.

\subsection{CÁLCULO DO ESCOAMENTO SUPERFICIAL DIRETO NA BACIA E NA REDE HIDROGRÁFICA}

Com a ferramenta Flow length (downstream) foi gerado o mapa escoamento superficial direto na bacia. Utilizando o raster calculator, foram obtidos os comprimentos do escoamento superficial direto na rede hidrográfica.

\subsection{TEMPO DE CONCENTRAÇÃO PELO MÉTODO DE KIRPICH}

É definido como o tempo necessário para que a água que cai no ponto mais distante da bacia chegue até a sua seção de controle. Este tempo de concentração, pode ser calculado conforme a Equação 1, a seguir:

$$
T C=57 \times{\frac{L^{30,385}}{H}}^{-10}
$$

Com a ferramenta raster calculator, foi calculado o tempo de concentração com base no Modelo Numérico de Terreno (MNT) e no comprimento do escoamento superficial direto.

\section{RESULTADOS}

A seguir, serão apresentados os produtos, contendo mapas e informações, gerados durante o processo de geoprocessamento dos dados. $\mathrm{O}$ mapa temático 1 apresenta a delimitação da área da bacia individualizada para a elaboração do trabalho. 
Bacia Hidrogáfica Individualizada
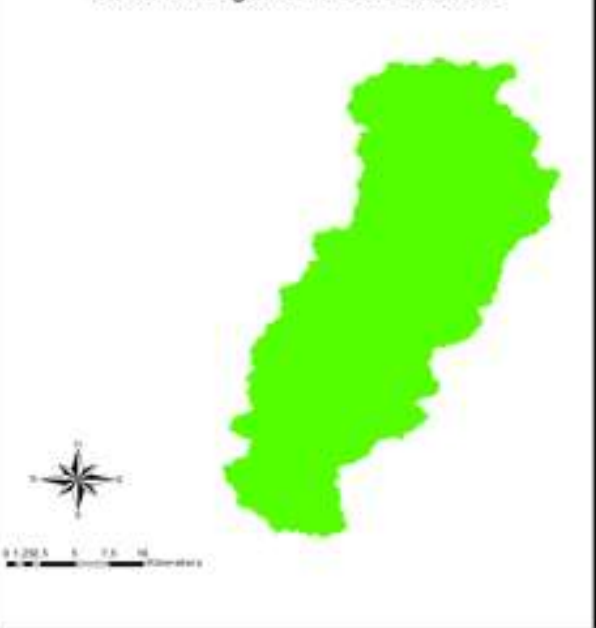

\section{Mapa Temático 1. Delimitação da Bacia Hidrográfica.}

Os mapas temáticos 2, 3 e 4 apresentam, respectivamente, os mapas do modelo numérico de terreno (MNT), da direção de fluxo e fluxo acumulado.

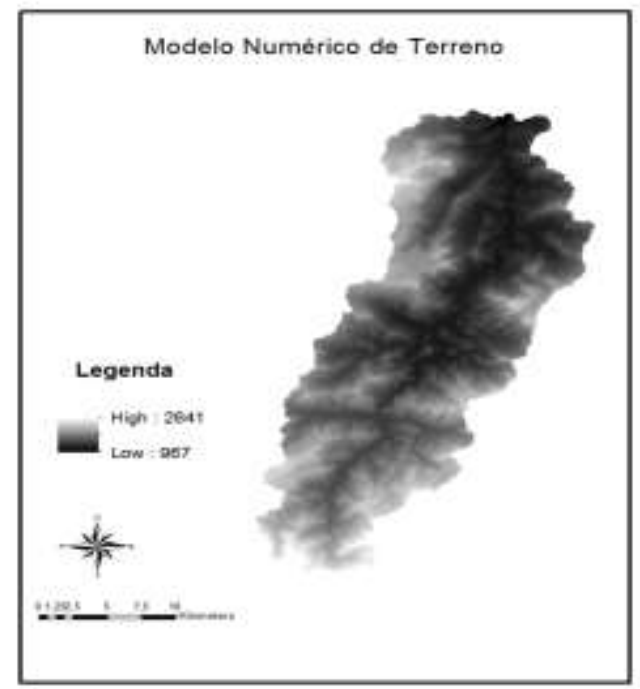

Mapa Temático 2.Modelo numérico de terreno (MNT) 


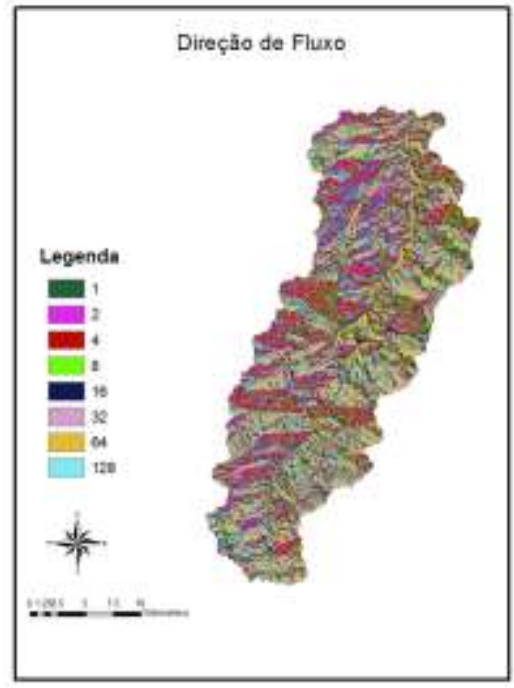

\section{Mapa Temático 3. Direção de Fluxo}

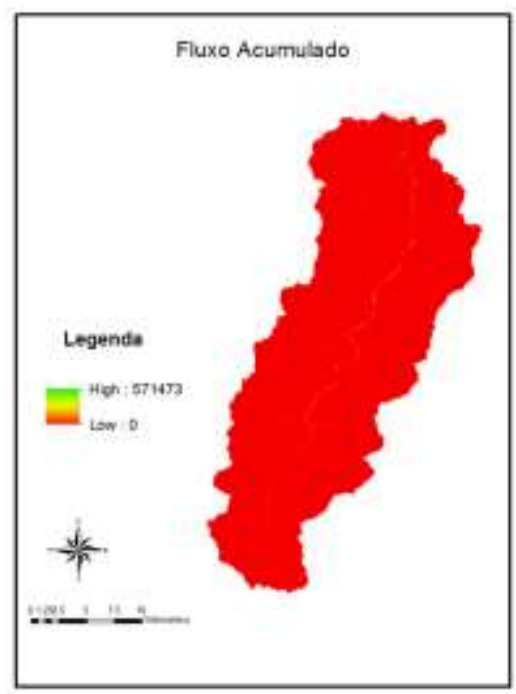

\section{Mapa Temático 4. Fluxo acumulado}

O Mapa Temático 5 representa a hidrografia da Bacia Hidrográfica Individualizada. 

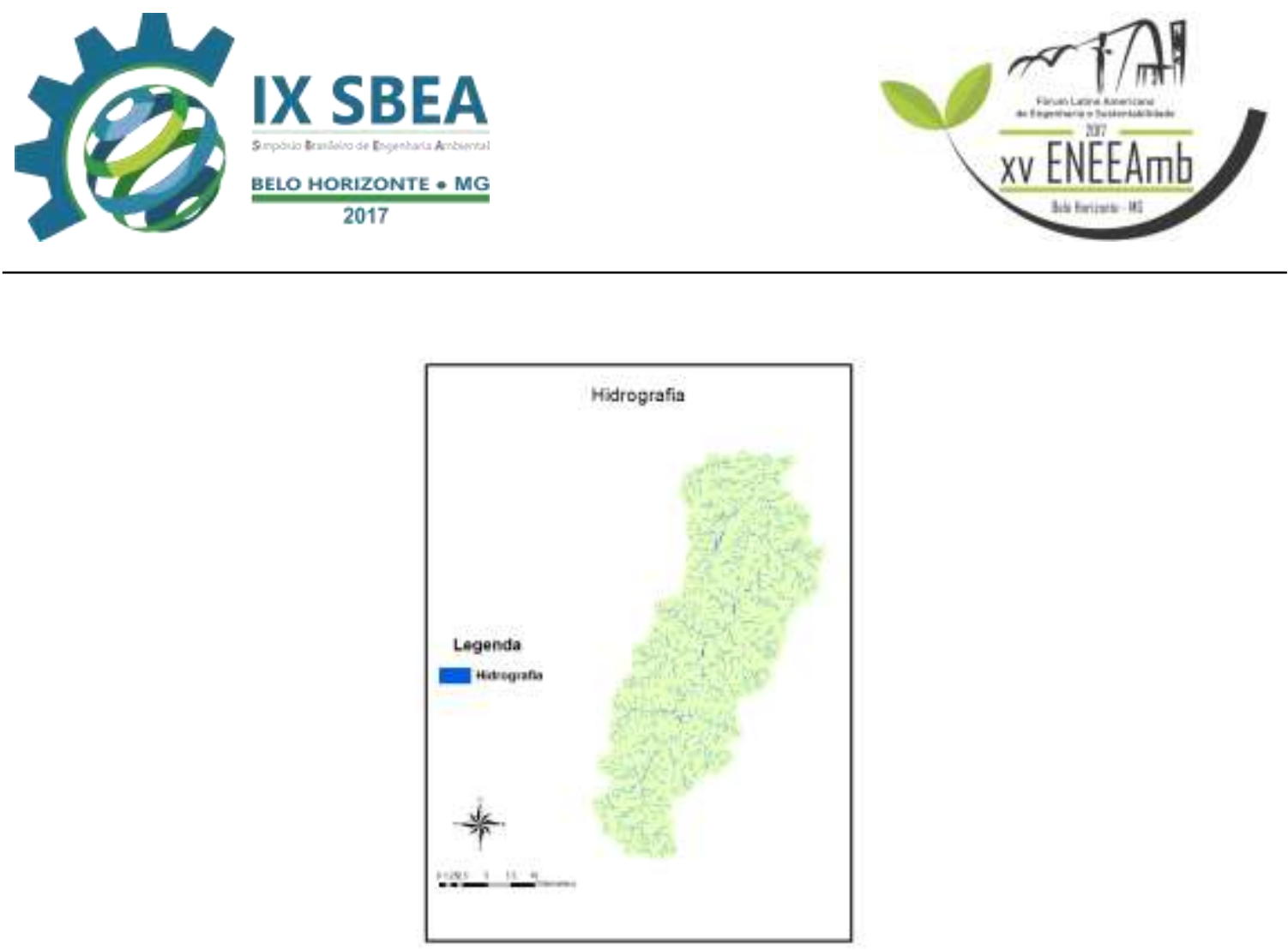

\section{Mapa Temático 5. Hidrografia}

Os mapas de declividade da bacia e da rede de drenagem estão representados nos Mapas Temáticos 6 e 7, respectivamente.

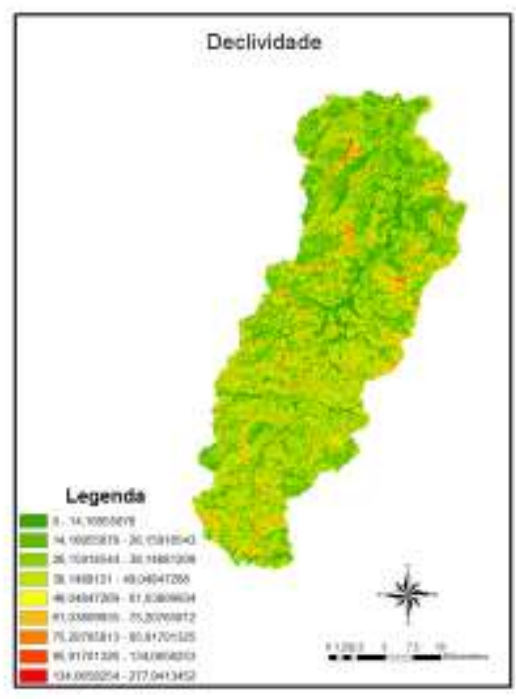

Mapa Temático 6. Mapa de declividade da bacia 

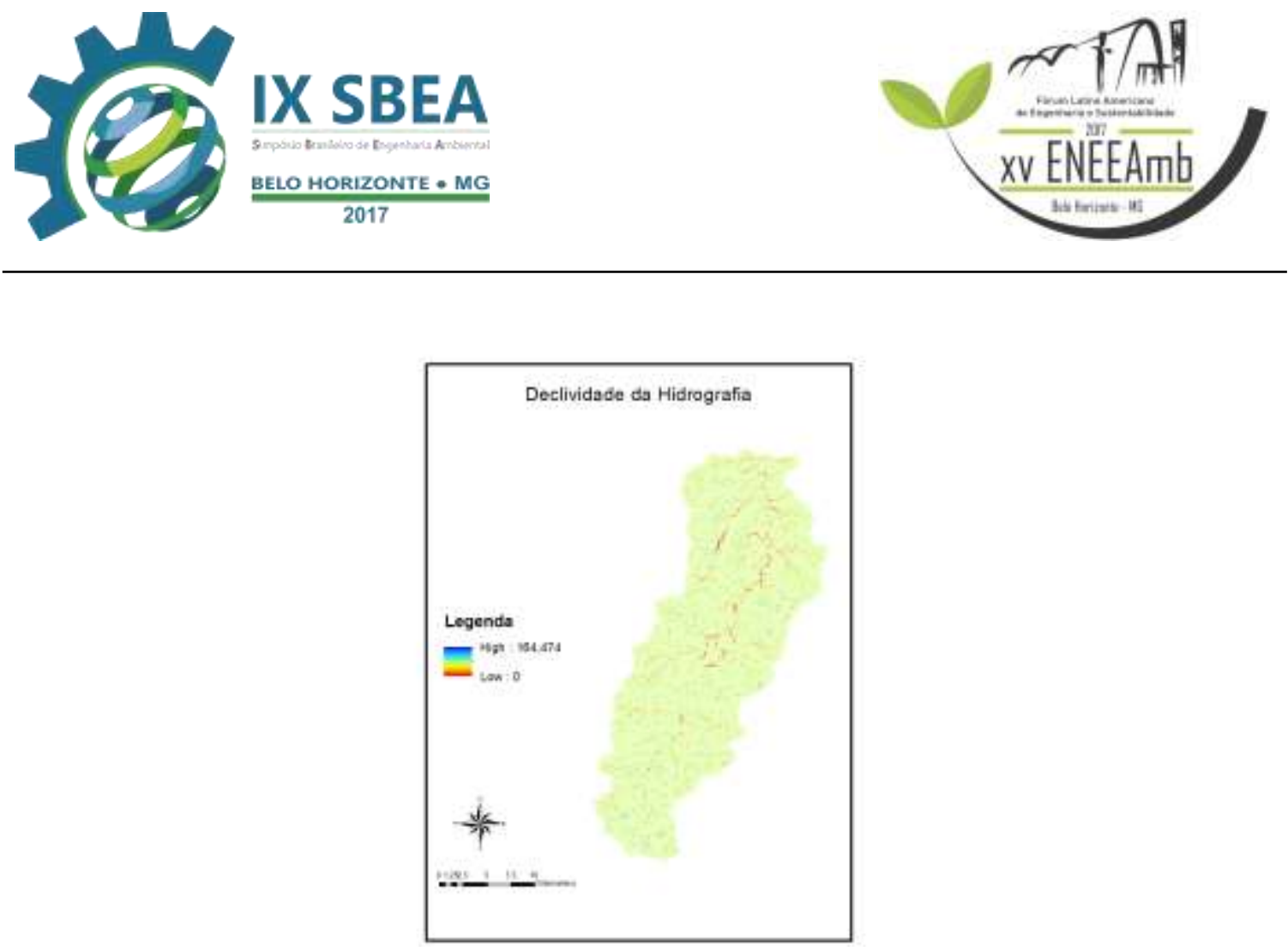

\section{Mapa Temático 7. Mapa de declividade da rede de drenagem.}

O Mapa Temático 8, a seguir, apresenta o escoamento superficial direto (ESD) da bacia individualizada.

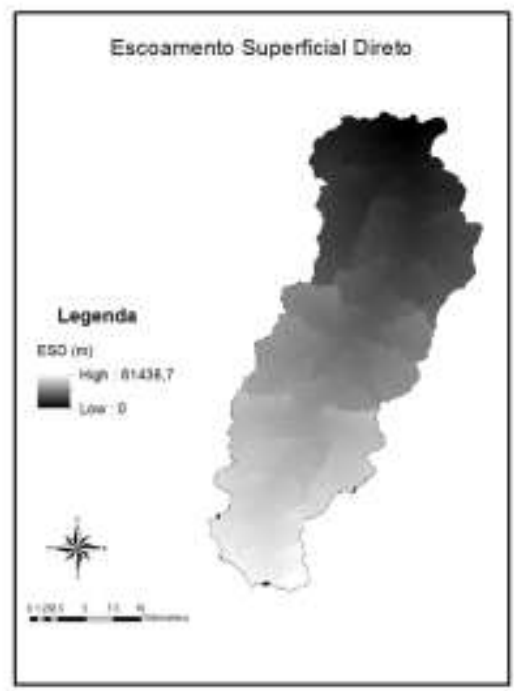

\section{Mapa Temático 8. Escoamento Superficial Direto (ESD)}

O comprimento do escoamento superficial está representado no Mapa Temático 9. Nas tabelas 1 e 2 encontram-se as características da Bacia Hidrográfica. A primeira tabela contém a ordem da Bacia Hidrográfica, bem como as altitudes mínima, média e máxima, sua área e perímetro. 


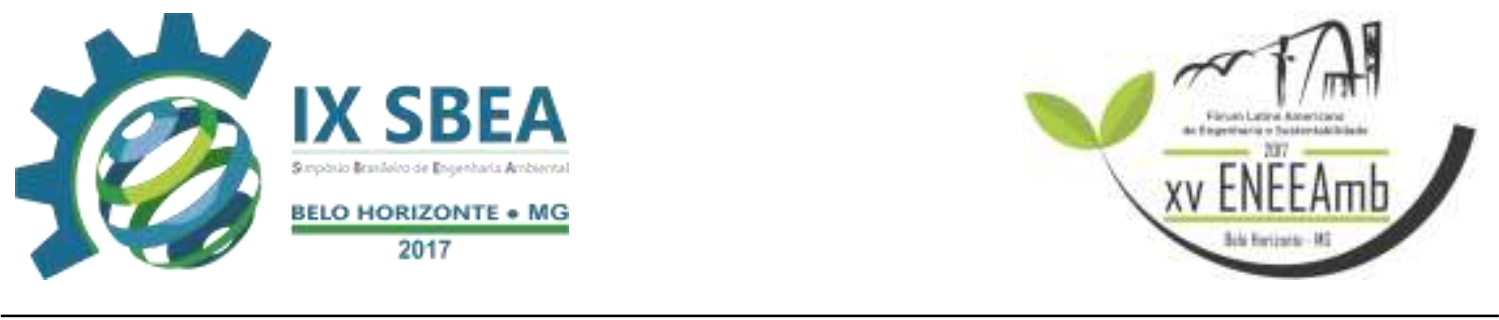

$\mathrm{Na}$ tabela 2 encontram-se as características da Bacia Hidrográfica relacionadas aos mapas gerados de comprimento do escoamento superficial direto da bacia e da rede hidrográfica, de declividades mínima, média e máxima da bacia e da rede de drenagem, e o tempo de concentração pelo método de Kirpich.

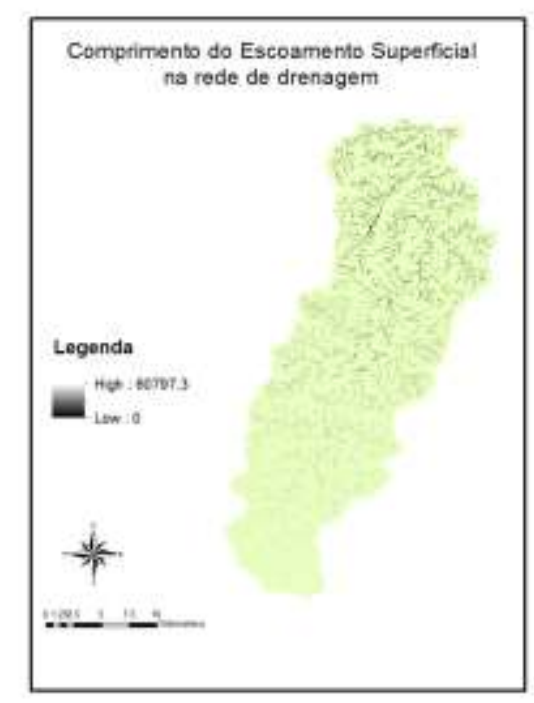

Mapa Temático 9. Comprimento do Escoamento Superficial na rede de drenagem.

Tabela 1: Dados da Bacia Hidrográfica individualizada.

\begin{tabular}{cc}
\hline DADOS & VALOR \\
\hline Área da Bacia Hidrográfica $\left(\mathbf{k m}^{2}\right)$ & 520,36 \\
Perímetro da Bacia Hidrográfica (km) & 140,77 \\
Altitude máxima (m) & 2641 \\
Altitude média (m) & 1543,5 \\
Altitude mínima (m) & 967 \\
Ordem da Hidrografia & 5
\end{tabular}

Tabela 2: Características da Bacia Hidrográfica individualizada.

\begin{tabular}{cc}
\hline DADOS & VALOR \\
\hline Comprimento do escoamento superficial na Bacia (km) & 61,44 \\
Comprimento do escoamento superficial na rede de drenagem (km) & 60,79 \\
Declividade máxima da Hidrografia (\%) & 164,47 \\
Declividade média da Hidrografia (\%) & 17,94 \\
Declividade mínima da Hidrografia (\%) & 0 \\
Declividade máxima da Bacia (\%) & 277,94 \\
Declividade média da Bacia (\%) & 35 \\
Declividade mínima da Bacia (\%) & 0 \\
Tempo de concentração - Kirpich (min) & 476,6 \\
\hline
\end{tabular}




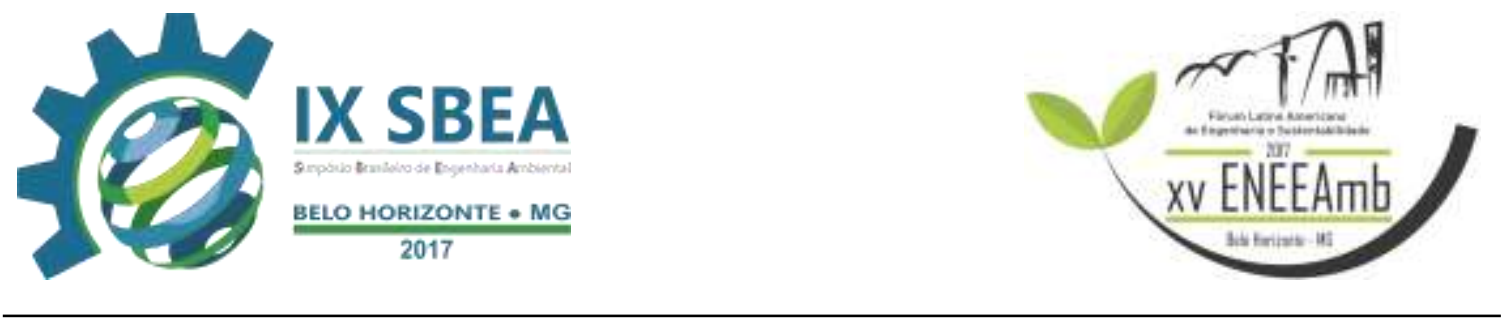

O Mapa Temático 10 apresenta o tempo de concentração, ou seja, o tempo necessário para o escoamento percorrer desde o ponto mais distante até a foz da bacia, sendo que o tempo máximo encontrado foi de 476,6 minutos.

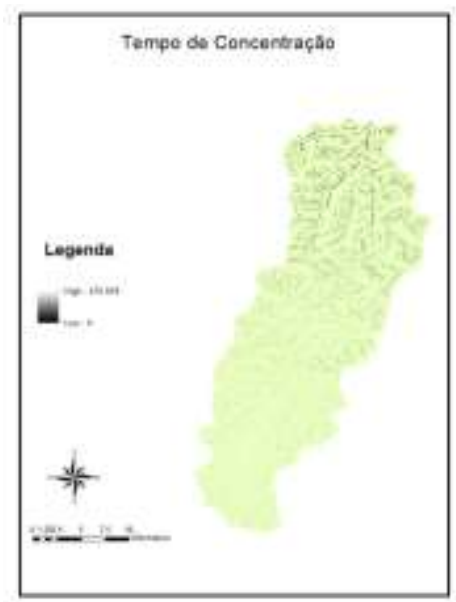

\section{Mapa Temático 10. Tempo de concentração calculado pela equação de Kirpich. CONCLUSÕES}

Os produtos de sensoriamento remoto são uma ferramenta indispensável para a atual gestão de recursos hídricos. Dados importantes podem ser facilmente obtidos através do processamento, tratamento e análise das imagens obtidas por satélites. Além da precisão dos dados obtidos, o processamento digital de imagens diminui a subjetividade de outros processos mais tradicionais.

Tais ferramentas auxiliam na prevenção, controle, monitoramento de impactos ambientais, e também na caracterização de bacias hidrográficas, que possuem grandes extensões, cujo trabalho de campo é dispendioso.

\section{REFERÊNCIAS BIBLIOGRÁFICAS}

Mello, C.R. (2013). Princípios e aplicações em sistemas agrícolas. Lavras. UFLA.

SOBRINHO, T.A. (2010). Delimitação Automática de Bacias Hidrográficas

Utilizando Dados SRTM. Engenharia Agrícola, p. 46-57 